\title{
Inclusion \& Cyberbullying: Which Ultimately Prevails?
}

\author{
Konstantinos Zimianitis \\ Athens, Greece \\ Email: zimkostas [AT] yahoo.gr
}

\begin{abstract}
ASBTRACT--- School bullying involves a range of aggressive behaviors aimed at causing harm to a person. This phenomenon is increasing in the student population at a global level. The continued evolution of technology and the use of technological tools in everyday life have contributed to the formation of so-called cyberbullying. In particular, increased use of mobile phones, social media, easy and fast internet access and anonymity in the digital world contribute to shaping the phenomenon.
\end{abstract}

Keywords--- Bullying, students, victimization, self-esteem

\section{INTRODUCTION}

Cyberbullying is characterized by the use of electronic forms of communication (telephone calls, text messages, images/videos, web pages, communication rooms, group conversations, e-mail, etc.) that allow the perpetrator to remain anonymous and cause discomfort to the victim. Cyberbullying has many forms including brawling, harassment, misleading, impersonation, and persistent stalking (Cantone et al., 2015). In effect, cyberbullying involves aggressive, repetitive behaviors that occur in the online environment by one or more individuals and have a negative impact on the mental and physical health of the victims (Grigoraki, Peraki\&Politi, 2014).

Cyberbullying is a modern phenomenon that occurs in minors. The researchconductedby Livingstone, Haddon, Gorzig and Olafsson (2011), which took place on a sample of 23,420 children and young individuals from different European countries, showed that $5 \%$ had been the victim of cyberbullying once a week, $4 \%$ once or twice per month and $10 \%$ less frequently.

Cyberbullying, as well as bullying in person, affect the life and psychosocial condition of individuals. Students who are victimized feel insecure and isolated both at school and at home while they are at high risk of anti-social behaviors, substance abuse and emotional disturbances (Cowie, 2011, Sourander et al., 2010). Electronic victimization is associated with lower self-esteem, higher social anxiety, and symptoms of depressionaffecting theindividual's well-being within and outside the school environment (Waasdorp\& Bradshaw, 2015).

The negative impact that cyberbullying has on the mental health of victims underlines the need to identify and reinforce the factors that can act as protection for the victims. The purpose of this paper is to study the role of classroom and students' psycho-cognitive characteristics in their electronic victimization.

\section{THE ROLE OF THE CLASSROOM IN CYBERBULLYING}

The study of cyberbullying has produced data on the role played by the age and the classroom, in which studentsstudy, in their victimization. Research in this field has displayed different results as there are studies showing that the phenomenon of cyberbullying and victimization is increasing in the early years of adolescence (12-15 years) while there are findings showing that there are negative correlations between age and cyberbullying (Matos, Vieira, Amado, Pessoa \& Martins, 2018).

One of the studiesfocusing on the differences in cyberbullying between classrooms is that of Aizenko and Kashy-Rosenbaum (2019), which was conducted withelementary, secondary and high school students in Israel. The purpose of the research was to study the degree of victimization of students who participated in group conversations in WhatsApp. The research results noted that the demographic characteristics of the students, and in particular the 
classroom-age pair, are significantly associated with victimization. More specifically, increased cyberbullying was seen in elementary school compared to secondary school and high school. The researchers attributed these results to the skills acquired by students as they grow psychosocially and transition from childhood to adolescence. What has been pointed out is that older students are better able to manage cyberbullying and thus protect themselves from victimization. Another research, the results of which show the negative correlation between age and victimization, is that of Schneider, O'donnell, Stueve and Coulter (2012). The research included adolescent students of the 9th, 10th, 11th and 12th grades, who were evaluated in relation to their exposure to in-person and onlinebullying. The results of the study indicate that 12th-grade students display a lower degree of involvement in cyberbullying than lower-class students.

However, there are research findings that show that older class students are at higher risk of victimization than those of the younger classes Del Rey, Elipe and Ortega-Ruiz (2012). For example, the research of Mark \&Ratliffe (2011) included students of the 6th, 7th and 8th grades. The results state that 8th-grade students have a higher degree of victimization compared to students in the previous classes. Such a positive correlation was also noted between the classroom and the causing of cyberbullying.

Finally, the classroom is also being examined from a further point of view,in connection with its role in the phenomenon of school bullying. More specifically, the specialists emphasize the educational context of the class attended by students who become perpetrators and victims. Within this framework, it has been argued that children participating in special education programs are more likely to be involved in school bullying incidents either as perpetrators or as victims in comparison with their peers attending school inclusion programs (Son, Parish, \& Peterson, 2012). One of the researches that examine the relationship between cyberbullying and the type of classroom is that of Heiman and OlenikShemesh (2015). This research took place with the participation of teenagers with and without learning difficulties attending general and special education classes. The results of the study revealed that students attending special education classes were more likely to exercise as well as to undergocyberbullying compared to students attending general education classes (inclusion).

The above evidence highlights the relationship that exists between the classroom and cyberbullying. The classroom, both as an educational context and as an indicator of the age of the students, is related to the development of cyberbullying in students of ordinary and abnormaldevelopment. However, the mixed results of the studiesunderline the existence of other characteristics associated with this phenomenon. These factors concern the students' personal and psycho-cognitive characteristics (Estell, 2009).

\section{THE ROLE OF PERSONAL TRAITS IN CYBERBULLYING}

One of the research subjectsin the field of cyberbullying is the study of the personality traits of the individuals involved in it. Experts attempt to identify the traits of a person that increase the likelihood of his involvement in cyberbullying. The identification of these traits can positively contribute to the development of effective interventions within the school framework to curb the phenomenon of cyberbullying (Zezulka\&Seigfried-Spellar, 2016).

A typical example of the researchers' effort to identify the personality traits of students involved in cyberbullying is the study of Alonso and Romero (2017). This study involved 910 adolescents who were evaluated for their involvement in the phenomenon and personality traits based on the model of the five personality factors. The results of the research showed that the victims of cyberbullying displayedto a higher degree the characteristics of openness toexperience and neuroticism, while the perpetrators displayed to a higher degree the characteristics of extroversion and openness to experience. The findings of this research are in line with those of the Corcoran, Connolly and O'Moore study (2012) involving 876 secondary school students. The results of the research highlighted the strong correlation between neuroticism and victimization.

Another research that examined students' personality traits and their relation to in-person and electronic bullying is that of van Geel, Goemans, Toprak and Vedder (2017). This study involved adolescents who were evaluated on the basis of the five major factors of personality, the characteristics of the dark triad and sadism. The results of the study show that cyberbullying is related to the characteristics of enjoyment and sadism. 
The review of research finds highlights the vital role of individuals' personalitytraits in their involvement in cyberbullying. These traits are examined during adolescence when the personality of individuals can be evaluated more easily due to students' maturity (Kowalski, Giumetti, Schroeder \&Lattanner, 2014).

\section{THE ROLE OF PSYCHO-COGNITIVECHARACTERISTICS IN CYBERBULLYING}

The victimization of students, through their involvement in cyberbullying, appears to be influenced by their psycho-cognitivecharacteristics. This means that certain characteristicsbased on psychological and cognitive processes can function as protection or increase the risk of victimization.

One of the psycho-cognitivecharacteristics that are related to the exercise andconfrontation of cyberbullying is self-esteem. Self-esteem refers to negative or positive considerations made by a person about himself. Self-esteem involves both cognitive and social dimensions. As regards the relation between self-esteem and cyberbullying, what is observed is that students with low self-esteem are more likely to exercise and face bullying than students with high selfesteemdo (Brighi et al., 2012). This claim has been confirmed by studies such as Patchin and Hinduja (2010). The research was carried out on a sample of 1963 elementary school students. The results of the research showed that both victims and perpetrators had lower self-esteem than that of students who were not involved in cyberbullying. The results agree with the latest research by Palermiti, Servidio, Bartolo and Costabile (2017) involving children and teenagers from Italy. The relationship between low self-esteem and cyberbullying can be explained by understanding the students' motives. More specifically, students with low self-esteem involved in cyberbullying attempt through this to enhance their self-esteem. On the other hand, students with low self-esteem may become victims of bullying because of their reduced ability to claim a positive attitude towards them (Safari, 2015).

The study of the psycho-cognitive characteristics of students involved in cyberbullying has also highlighted the factorof assertiveness that can act asprotection for victims. Individualscharacterized by assertiveness are able to develop positive relationships with others, to prevent victimization against themselves and to express a range of positive and negative thoughts, such as remorse (Avsar\&Alkaya, 2017). According to Riebel, Jäger and Fischer (2009), assertiveness can be seen as a cognitive strategy that addresses the way an individual resists or manages the aggressive behaviors aimed at him. In the case of cyberbullying, assertive behavior concerns an internal negotiation process. More specifically, students who are victimized do not seek help from a more "powerful" person such as parents or teachers, but instead, try to solve the problem autonomously. The solution to the problem comes through the attempt to analyze the perpetrator's behavior and motivation. In this way, the student understands the behavior aimed at him and empowers himself to deal with it autonomously (Riebel et al., 2009).

The use of assertive behavior as a way of dealing with cyberbullying was examined by Machmutow, Perren, Sticca and Alsaker (2012). This research involved 765 Swiss students who were evaluated in terms of managing strategies, victimization and depressive symptoms. The results of the study indicate that there are significant correlations between the strategy of assertive behavior, victimization and depressive symptoms. Students who are victimized use this managing strategyto a great extent, while girls use it more often than boys. Frequent use of the strategy has been associated with higher levels of depressive symptoms. Researchers explain these unexpected results by indicating that the victim's contact with the perpetrator in the context of assertion is likely to traumatize the latter and increase his depressive symptoms.

The above shows the critical role played by students' psycho-cognitive characteristics in their involvement in school bullying. The level of self-esteem of minors and the strategies they use to cope with victimization can affect their future involvement in the phenomenon (Menesini\& Spiel, 2014).

\section{CONCLUSIONS}

Cyberbullying is a modern problem faced by the student population. The involvement of students in school bullying depends on many factors, such as school environment, age, and psycho-cognitive characteristics. This means that students are likely to be affected by factors that put them at high risk of victimization (Medina, Manzuoli, Duque \&Malfasi, 2018). 
The results of this paper can be taken into consideration in the design and implementation of effective interventions for the prevention and/or reduction of the phenomenon. Interventions have to take place since the early years of primary education in order to strengthen the characteristics of students which functionas a protection against victimization. In this way, students will be able to effectively protect and manage the phenomenon avoiding the negative impact it has on their well-being (Froeschle, Mayorga, Castillo \& Hargrave, 2008).

\section{BIBLIOGRAPHICAL REFERENCES}

- Aizenkot, D., \&Kashy-Rosenbaum, G. (2019). Cyberbullying victimization in WhatsApp classmate groups among Israeli elementary, middle, and high school students. Journal of Interpersonal Violence, 1-22.

- Alonso, C., \& Romero, E. (2017). Aggressors and victims in bullying and cyberbullying: A study of personality profiles using the five-factor model. The Spanish Journal of Psychology, 20(e76), 1-14.

- Avşar, F., \&Alkaya, S. A. (2017). The effectiveness of assertiveness training for school-aged children on bullying and assertiveness level. Journal of Pediatric Nursing, 36, 186-190.

- Brighi, A., Melotti, G., Guarini, A., Genta, M. L., Ortega, R., Mora-Merchán, J., ... \& Thompson, F. (2012). Self-esteem and loneliness in relation to cyberbullying in three European countries. Cyberbullying in the Global Playground: Research from International Perspectives, 32-56.

- Cantone, E., Piras, A. P., Vellante, M., Preti, A., Daníelsdóttir, S., D’Aloja, E., ... \&Bhugra, D. (2015). Interventions on bullying and cyberbullying in schools: A systematic review. Clinical Practice and Epidemiology in Mental Health: $C P$ \& EMH, 11 (Suppl 1 M4), 58-76.

- Corcoran, L., Connolly, I., \&O'Moore, M. (2012). Cyberbullying in Irish schools: An investigation of personality and self-concept. The Irish Journal of Psychology, 33(4), 153-165.

- Cowie, H. A. (2011). Coping with the emotional impact of bullying and cyberbullying: How research can inform practice. International Journal of Emotional Education, 3(2), 50-56.

- Del Rey, R., Elipe, P., \& Ortega-Ruiz, R. (2012). Bullying and cyberbullying: Overlapping and predictive value of the co-occurrence. Psicothema, 24(4), 608-613.

- Estell, D., Farmer, T., Irvin, M., Crowther, A., Akos, P., \&Boudah, D. (2009). Students with exceptionalities and the peer group context of bullying and victimization in late elementary school. Journal of Child and Family Studies, 18(2), 136-150.

- Froeschle, J. G., Mayorga, M., Castillo, Y., \& Hargrave, T. (2008). Strategies to prevent and heal the mental anguish caused by cyberbullying. Middle School Journal, 39(4), 30-35.

- Grigoraki, M., Peraki, F., \& Politi, A. (2016). Online bullying in childhood and adolescence: investigating the phenomenon as manifested in social media. Panhellenic Conference of Education Sciences, 2014 (2), 663-672.

- Heiman, T., \&Olenik-Shemesh, D. (2015). Cyberbullying experience and gender differences among adolescents in different educational settings. Journal of Learning Disabilities, 48(2), 146-155.

- Kowalski, R. M., Giumetti, G. W., Schroeder, A. N., \&Lattanner, M. R. (2014). Bullying in the digital age: A critical review and meta-analysis of cyberbullying research among youth. Psychological Bulletin, 140(4), 10731137.

- Livingstone, S., Haddon, L., Gorzig, A. and Olafsson, K. (2010) Risks and Safety on the Internet. London: London School of Economics. 
- Machmutow, K., Perren, S., Sticca, F., \&Alsaker, F. D. (2012). Peer victimisation and depressive symptoms: can specific coping strategies buffer the negative impact of cybervictimisation?.Emotional and Behavioural Difficulties, 17(3-4), 403-420.

- Mark, L., \&Ratliffe, K. T. (2011). Cyber worlds: New playgrounds for bullying. Computers in the Schools, 28(2), 92-116.

- $\quad$ Matos, A. P., Vieira, C. C., Amado, J., Pessoa, T., \& Martins, M. J. D. (2018). Cyberbullying in Portuguese schools: Prevalence and characteristics. Journal of School Violence, 17(1), 123-137.

- Medina, C. L., Hennig Manzuoli, C., Duque, L. A., \&Malfasi, S. (2018). Cyberbullying: tackling the silent enemy. International Journal of Inclusive Education, 1-12.

- Menesini, E., \& Spiel, C. (2012). Introduction: Cyberbullying: Development, consequences, risk and protective factors. European Journal of Developmental Psychology, 9(2), 163-167.

- Palermiti, A. L., Servidio, R., Bartolo, M. G., \&Costabile, A. (2017). Cyberbullying and self-esteem: An Italian study. Computers in Human Behavior, 69, 136-141.

- Patchin, J. W., \& Hinduja, S. (2010). Cyberbullying and self-esteem. Journal of School Health, 80(12), 614621.

- Riebel, J. R. S. J., Jäger, R. S., \& Fischer, U. C. (2009). Cyberbullying in Germany-an exploration of prevalence, overlapping with real life bullying and coping strategies. Psychology Science Quarterly, 51(3), 298314.

- Safaria, T. (2015). Are daily spiritual experiences, self-esteem, and family harmony predictors of cyberbullying among high school student. International Journal of Research Studies in Psychology, 4(3), 23-33.

- Schneider, S. K., O'donnell, L., Stueve, A., \& Coulter, R. W. (2012). Cyberbullying, school bullying, and psychological distress: A regional census of high school students. American Journal of Public Health, 102(1), $171-177$.

- Son, E., Parish, S. L., \& Peterson, N. A. (2012). National prevalence of peer victimization among young children with disabilities in the United States. Children \& Youth ServicesReview, 34(8), 1540-1545.

- Sourander, A., BrunsteinKlomek, A. B., Ikomen, M., Lindroos, J., Luntamo, T., Koskelainen, M., Ristkari, T. and Helenius, H. (2010) Psychosocial risk factors associated with cyberbullying among adolescents. Archives of General Psychiatry, 67(7), 720-728.

- $\quad$ van Geel, M., Goemans, A., Toprak, F., \&Vedder, P. (2017). Which personality traits are related to traditional bullying and cyberbullying? A study with the Big Five, Dark Triad and sadism. Personality and Individual Differences, 106, 231-235.

- Waasdorp, T. E., \& Bradshaw, C. P. (2015). The overlap between cyberbullying and traditional bullying. Journal of Adolescent Health, 56(5), 483-488.

- Zezulka, L. A., \&Seigfried-Spellar, K. (2016). Differentiating cyberbullies and Internet trolls by personality characteristics and self-esteem. Journal of Digital Forensics, Security and Law, 11(3), 7-26. 